\title{
The Process of Development of Thyroidectomy Cells from the so-called Thyrotrophs
}

\author{
YASUNOSUKE KIGUCHI \\ Department of Anatomy, Jikei University School of Medicine, \\ Minato-ku, Tokyo 105
}

\begin{abstract}
Synopsis
The process of development of thyroidectomy (TX) cells from the so-called thyrotrophs (the II-type cells by Yoshimura et al., 1977) was electron-microscopically investigated at intervals of $12 \mathrm{hr}, 1,3,5,7$ and 14 days after TX. Cytological changes of the II-type cells vary from cell to cell even at the same intervals after TX. From $12 \mathrm{hr}$ to 5 days, the II-type cells are characterized by the deprivation of secretory granules and the enlargement of cell size. When extensively degranulated, the II-type cells appear as vesiculated cells with a round or oval shape, resembling the LH-gonadotrophs (the III-type cells). The frequent detection of III- and IV-type cells (FSH-gonadotrophs) is in striking contrast with the infrequent detection of IItype cells within $12 \mathrm{hr}$ and 1 day. Some pre-existed IV-type cells show retrogressive signs after TX. Some other IV-type cells are moderately granulated, at 1, 3 and 5 days, followed by the deprivation of the stored secretory granules, resulting in the vesiculated cells. These cells begin to appear at 3 days and increase in number at 5 and 7 days, despite the individual disparity in development. They may be the immature TX-cells characterized by the closure of Golgi lamellae, and by granules of low density in the small, irregularly shaped cisternae. They gradually increase in dimensions with the lapse of time. Degranulation and accumulation of large cisternae with progressive sedimentation of intracisternal granules may account for the maturation of TX-cells. By 14 days the maximal diameter of the mature TX-cells becomes 3-4 times as large as that of an acidophil. From the present observations, it is tentatively concluded that TX cells may not directly develop from the II-type cells, but indirectly through the III- or IV-type cells; and that the TX-cells may not be hyperfunctioning thyrotrophs, but rather dysfunctioning basophils.
\end{abstract}

The large vesiculated basophils particularly found in the pituitaries from the rats thyroidectomized or treated with thiouracil have been called "TX-cells". They are characterized by the packages of dilated cisternae in which are deposited dense granules (Rosa and D'Angelo, 1974). Since these vesiculated cells appear either after TX or with long-term injections of large doses of TRH, despite no intracisternal granules (Stratmann et al., 1973; Shiino

Received July 19, 1977. and Rennels 1975), they have been regarded as hyperfunctional thyrotrophs. Vesiculation and degranulation represent two major cytological signs of hyperfunction. Previous investigators, however, have failed to adduce the morphological evidence of the entire developmental course from the normal thyrotrophs (II-type cells by Yoshimura et al., 1977) to TX-cells, although there is consensus through immunohistochemical and radioautographical investigations that the TXcells develop from the thyrotrophs (Goluboff et al., 1970; Baker and Yu, 1971; Shiino et 
al., 1973 ; Stratmann et al., 1972; Moriary and Tobin, 1976). Shiino and Rennels (1975) classified three transitional cells between the thyrotrophs and TX-cells in the pituitary grafts of rats chronically injected with TRH (100 or $200 \mu \mathrm{g} /$ day). It seems difficult, however, to observe the initial changes of the thyrotrophs through the chronic experiment, because the chronic experiment is not suitable for adducing the morphological findings responding to the rapid rise of serum $\mathrm{TSH}$ concentration immediately afrer TX (Mess, 1958; Salaman, 1964; Davis and Borger, 1973). In this sense, it is necessary to carry out acute or subacute experiments, and we have given special attention to the early morphological response to the II-type cells in this study.

According to Elftman et al. (1958), it is difficult to establish the origin of the TX-cell without confusion, because the typical thyrotroph has usually disappeared prior to the full development of TX-cell. The purpose of this study is to validate, at the electron-microscopic level, whether TX-cells are merely hyperfunctional thyrotrophs or develop indirectly through the III- or IV-type cells (so-called LH- or FSH-gonadotrophs) from the II-type cells in accordance with a working hypothesis of the secretory cycle of the basophil (Yoshimura et al., 1977).

\section{Materials and Methods}

Surgical thyro-parathyroidectomy was carried out on the Wistar-Imamichi 45-day-old male rats. The animals were sacrificed at the following intervals, $12 \mathrm{hr}, 1,3,5,7$ and 14 days, respectively. The groups of each interval consisted of 5 rats. Intact 5 rats under the same condition served as the control.

Pituitary tissues were fixed in a 3\% glutaraldehyde

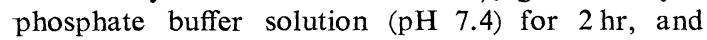
fixed again in a buffered (phosphate and veronal

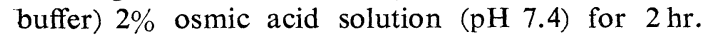
After fixation, the tissues were dehydrated in an ascending ethanol and embedded in Epon. Thin sections were made with a Porter-Blum ultratome, and stained with saturated uranyl acetate and with a lead solution. The sections were examined with the JEM $100 \mathrm{~B}$ electronmicroscope.

\section{Results}

Primary deprivation of secretory granules from the so-called thyrotrophs (the II-type cells) following $T X$

The normal so-called thyrotrophs (the II-type cells) from the adult male rats are elongated, polygonal, oval and sometimes lean in shape. They are either poor or rich in cytoplasm according to their functional state. The rough endoplasmic reticulum (RER) is arranged in numerous parallel arrays of tubular cisternae, or sometimes in a slightly dilated form. The Golgi apparatus is not prominent. Secretory granules $100-200 \mathrm{~nm}$ in diameter are scattered throughout the cytoplasm with a tendency to accumulate focally in a part of the cytoplasm, but they are not distributed in a row along the cytoplasmic membrane. Fig. 1 shows a II-type cell provided with a remarkable accumulation of secretory granules.

The normal II-type cells are susceptible to change in their fine structures during the intervals of $12 \mathrm{hr}, 1,3$ and 5 days after TX. Their fine structural changes show diversity from cell to cell even at the same intervals. Within the first 5 days after TX, the TX-cells have not yet well developed. An interval of more than 7 days is required for the development of typical TX-cells. In most of II-type cells, secretory granules $100-200 \mathrm{~nm}$ in size were reduced in number from the central area of cytoplasm within $12 \mathrm{hr}$, but tended to accumulate at the periphery of the cell-body (Fig. 2). The exocytotic picture of the secretory granules through the cytoplasmic membrane is not observed. Despite the temporal loss of secretory granules from the II-type cells afcer TX, the remaining granules are neither reduced in electron density nor in size. 

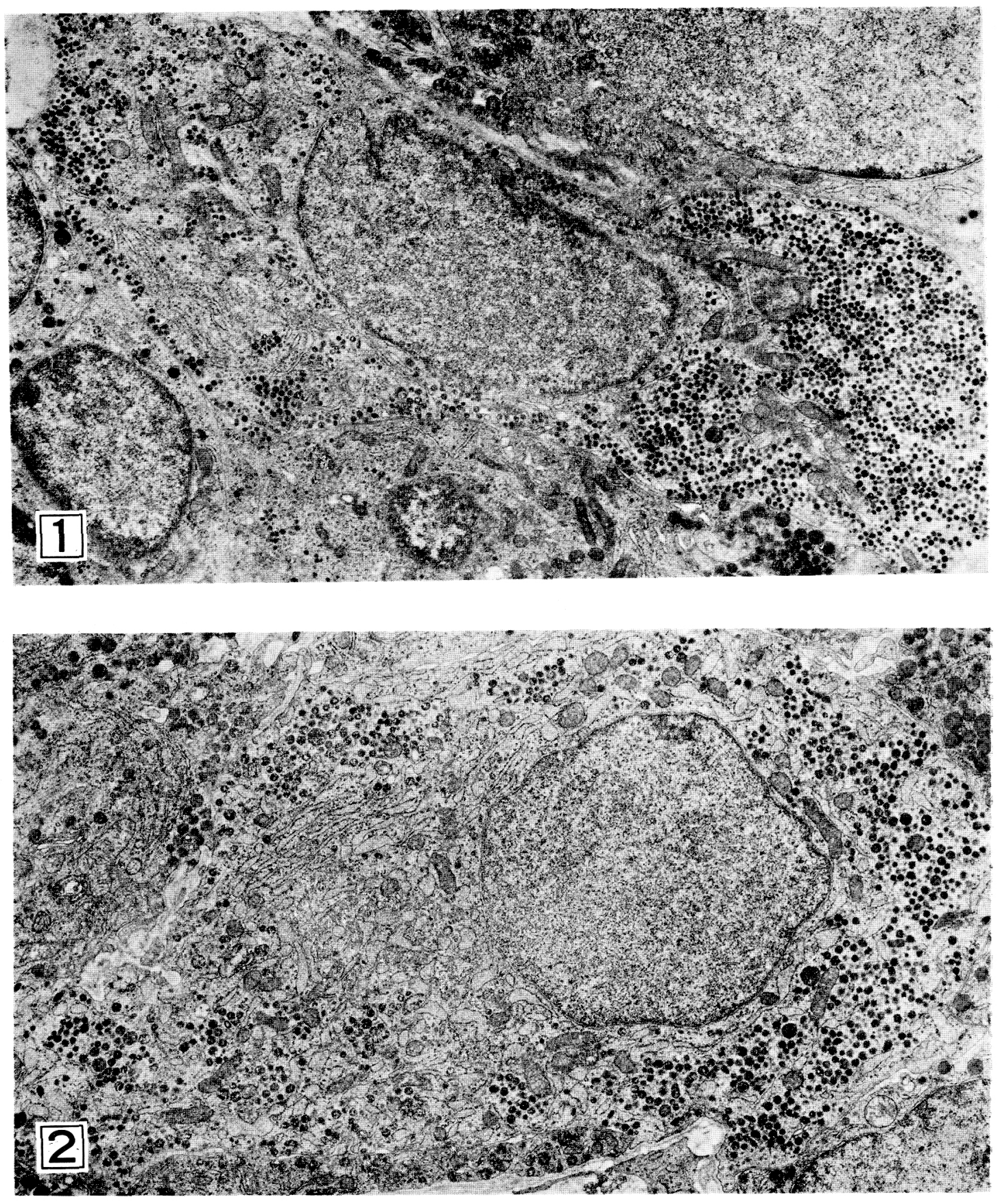

Fig. 1. A II-type basophil (classical thyrotroph) from a normal control rat. Most of secretory granules of $100-200 \mathrm{~nm}$ in diameter accumulate in the periphery of the cytoplasm. $\times 6600$.

Fig. 2. Slight deprivation of the secretory granules from a II-type basophil. A small number of secretory granules remain in the central area of the cytoplasm, while many secretory granules accumulate in the peripheral area, $12 \mathrm{hr}$ after TX. $\times 9000$. 

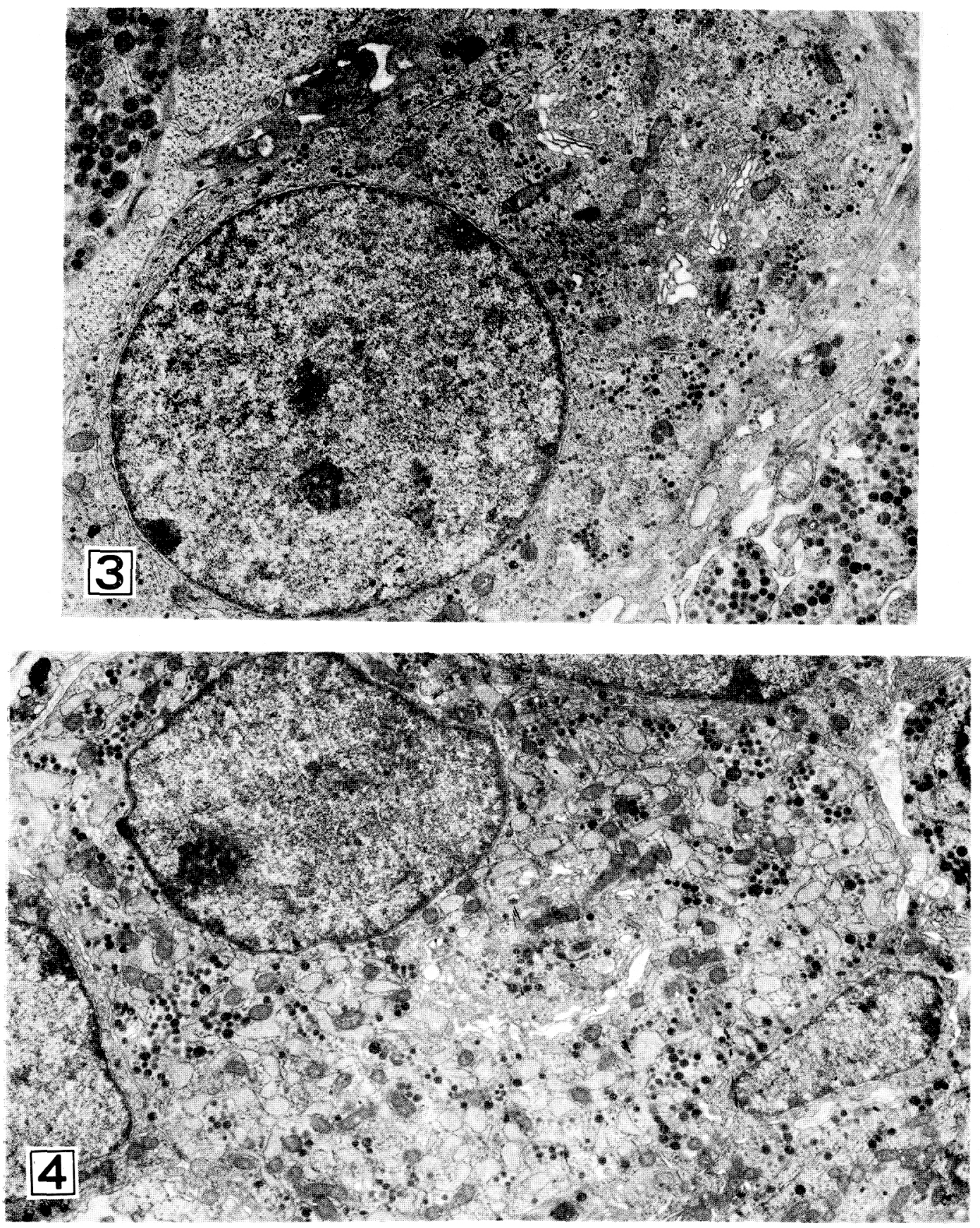

Fig. 3. A II-type cell with a remarkable degranulation, one day after TX. Narrow RER and delated lamellae of the Golgi apparatus are noted. $\times 7500$.

Fig. 4. A vesiculated III-type basophil (classical LH-gonadotroph), characterized by vesiculated RER and the Golgi body with dilated lamellae. Secretory granules rather disperse throughout the cytoplasm, 3 days after TX. $\times 6000$. 
However, there were some other oval basophils characerized by remarkable deprivation of secretory granules (Fig. 3). These cells are occasionally detected throughout the interval from $12 \mathrm{hr}$ to 5 days; the narrow and delicate cisternae of RER are distributed at random and stepwisely. The circular arrangement of dilated Golgi lamellae is located at the juxtanuclear position. In addition, during the interval from $12 \mathrm{hr}$ to 5 days, another vesiculated and oval basophil is occasionally detected (Fig. 4). This cell may correspond to the III-type cell (Yoshimura et al., 1977) because dilated RER is transformed into independent cisternae filled with an electron opaque substance. This cell keeps low granularity after the depletion of secretory granules. The circular arrangement of somewhat dilated Golgi lamellae is prominent.

Storage of secretory granules in the IIIor IV-type basophils following TX

The oval hypergranulated III-type cells are frequently observed intermingled with the less granulated III-type cells at $12 \mathrm{hr}$, 1 and 3 days (Fig. 5). Thus, the III-type cells give rise to further granulation. The electron dense secretory granules $100-250 \mathrm{~nm}$ in diameter may be newly formed, accumulating prior to the onset of dilatation of RER (Fig. 5). The circular arrangement of dilated Golgi lamellae is typical in them. Many large vesiculated basophils (IV-type cells by Yoshimura et al. 1977) contain a moderate accumulation of secretory granules $200-250 \mathrm{~nm}$ in diameter within 3 or 5 days (Fig. 6). This type of basophil after TX is characterized by the closure of Golgi lamellae. The two opposite Golgi membranes are arranged in parallel arrays, as if a bundle of osmiophilic membranes. Thus, the closure of Golgi lamellae is an initial sign of development into the TXcells, because the Golgi lamellae are commonly dilated in the representative IV-type basophils. There was no morphological evidence that all the II-type cells completely disappear during the early stage from $12 \mathrm{hr}$ to 5 days, in which degranulated II-type basophils still survive in small numbers. Infrequent detection of the IItype cells at the electron-microscopic level was in striking contrast with the frequent detection of III- and IV-type cells.

The IV-type cells which were already in the gland prior to TX usually exhibited cytological signs of suppression or dysfunction (Fig. 7). The degenerative process is postulated to occur as follow: 1) $\mathrm{Ag}$ glutination of dilated endoplasmic reticulum anastomosing with each other, 2) Nuclear pycnosis, 3) High density of ground matrix. On the other hand, the IV-type cells which may be supposed to have been newly originated from the II-type cells in response to TX can be easily distinguished from the old degenerating IV-type cells by their fine structures (compare Fig. 7 with Fig. 6).

Full development into TX-cells and secondary deprivation of the secretory granules

During the interval from 1 to 5 days, some IV-type cells were deprived of the secretory granules coincident with a slight modification of the cell contour. As observed in Fig. 8, within 3 days, secretory granules are conspicuously dispersed within an ovoid or polygonal, highly vesiculated cell, in which Golgi lamellae are narrow. In this vesiculated cell, numerous small cisternae of RER are distorted or coalesced to form the large ones of irregular shape. The small granules of low electron density begin to be deposited in some cisternae (arrow in Fig. 8). The formation of large cisternae of RER proceeds extensively in this kind of cells within 7 or 14 days. Eventually, it becomes a young TX-cell which contains numerous cisternae in which small granules of low density also begin to be deposited (arrow in Fig. 9). The Golgi lamellae are slightly recovered from 
Endocrinol Japon.

February, 1978
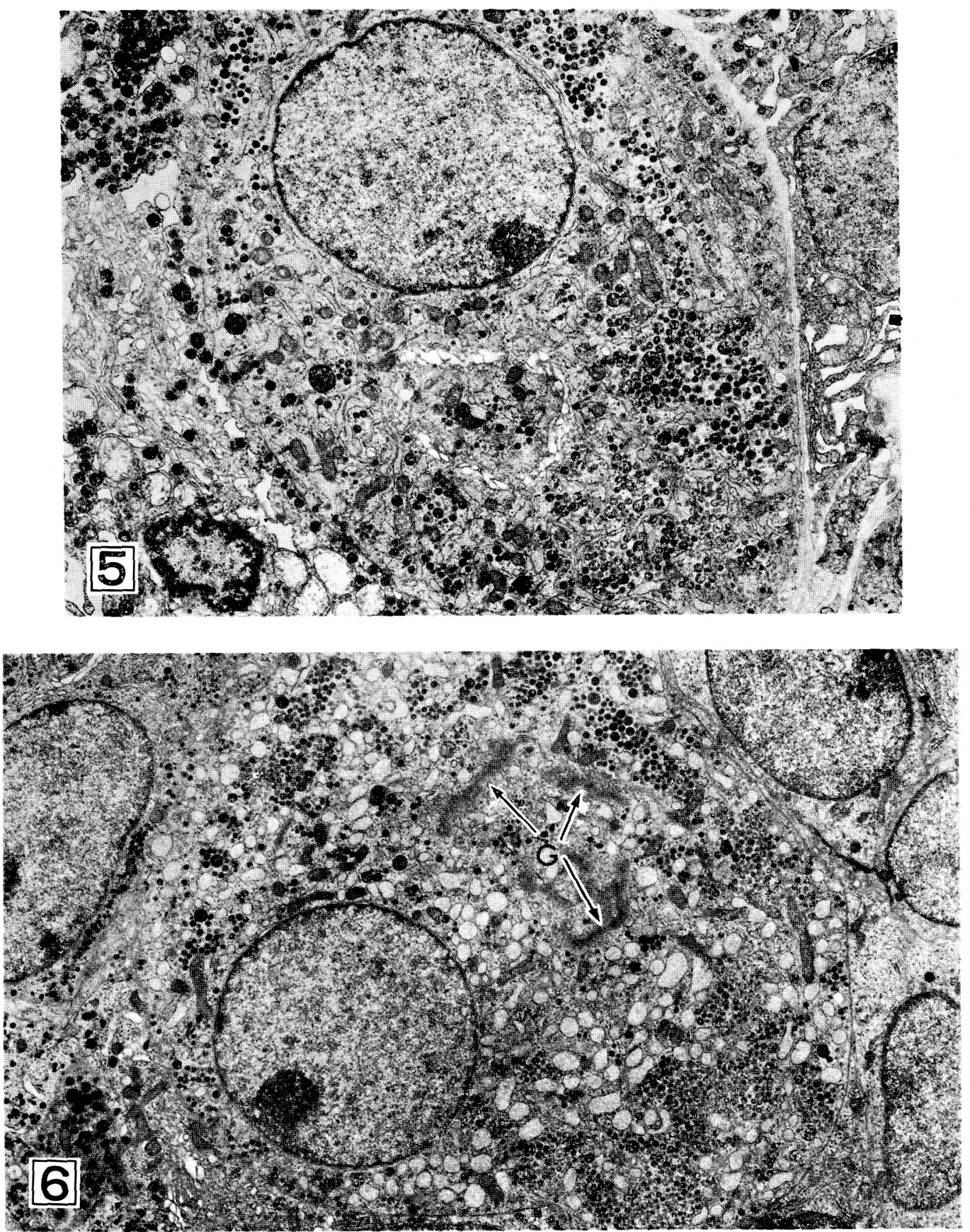

Fig. 5. A granulated III-type basophil (classical LH-gonadotroph). The secretory granules of 100 $250 \mathrm{~nm}$ in diameter accumulate in various area of the cytoplasm. Golgi lamellae are dilated prominently, 3 days after TX. $\times 6300$.

Fig. 6. A vesiculated IV-type basophil (classical FSH-gonadotroph). Cisternal enlargement of RER, a moderate accumulation of secretory granules and narrow Golgi lamellae (G) are here disclosed, 1 day after TX. $\times 5500$. 

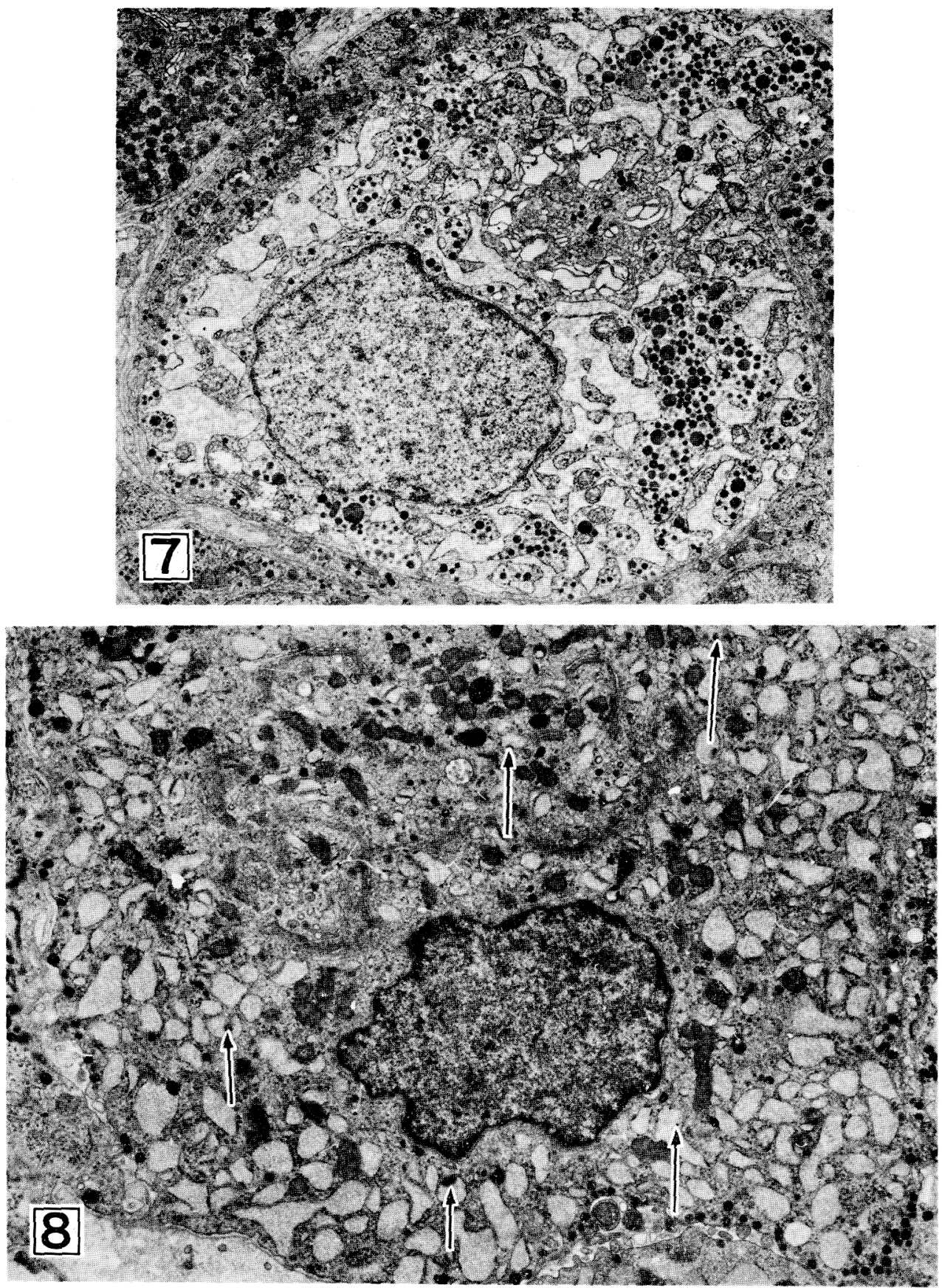

Fig. 7. Degenerating IV-type basophil characterized by coalescent cisternae of RER and the pycnotic nucleus, 3 days after TX. $\times 5500$.

Fig. 8. A polygonal immature TX-cell. The cell body is occupied by cisternae of RER, in some of which small granular structures are recognized (arrows). A closure of Golgi lamellae is evident. This cell resembles ultrastructurally the vesiculated IV-type basophil, 3 days after TX. $\times 7500$. 


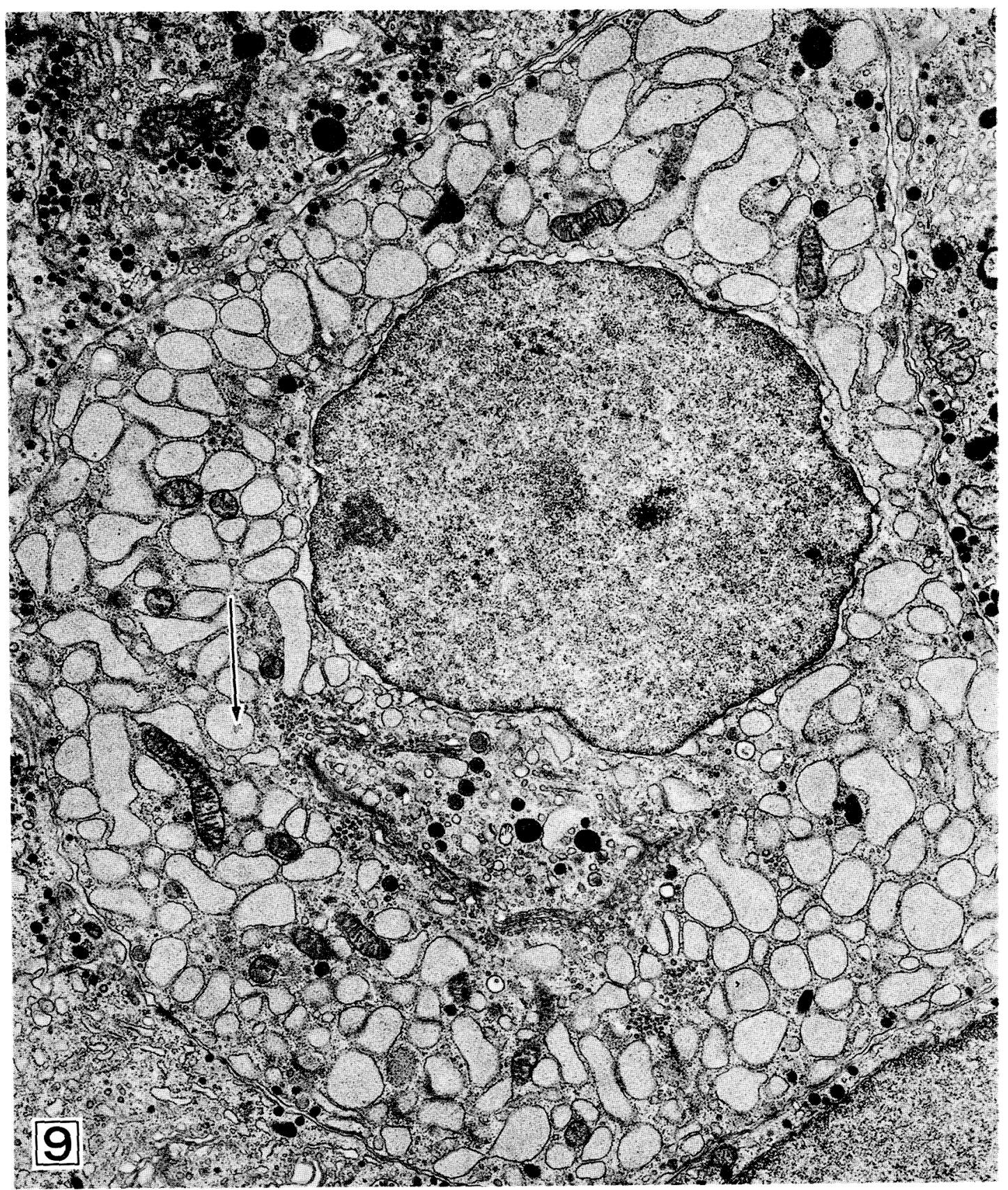

Fig. 9. A young TX-cells. The cytoplasm is occupied by cisternae of various sizes. Small granular structures (arrow) of low density are deposited in the cisternae. Some of the narrow Golgi lamellae appear to dilate. Lysosomal bodies are scattered in the Golgi area, 7 days after TX. $\times 13000$. 


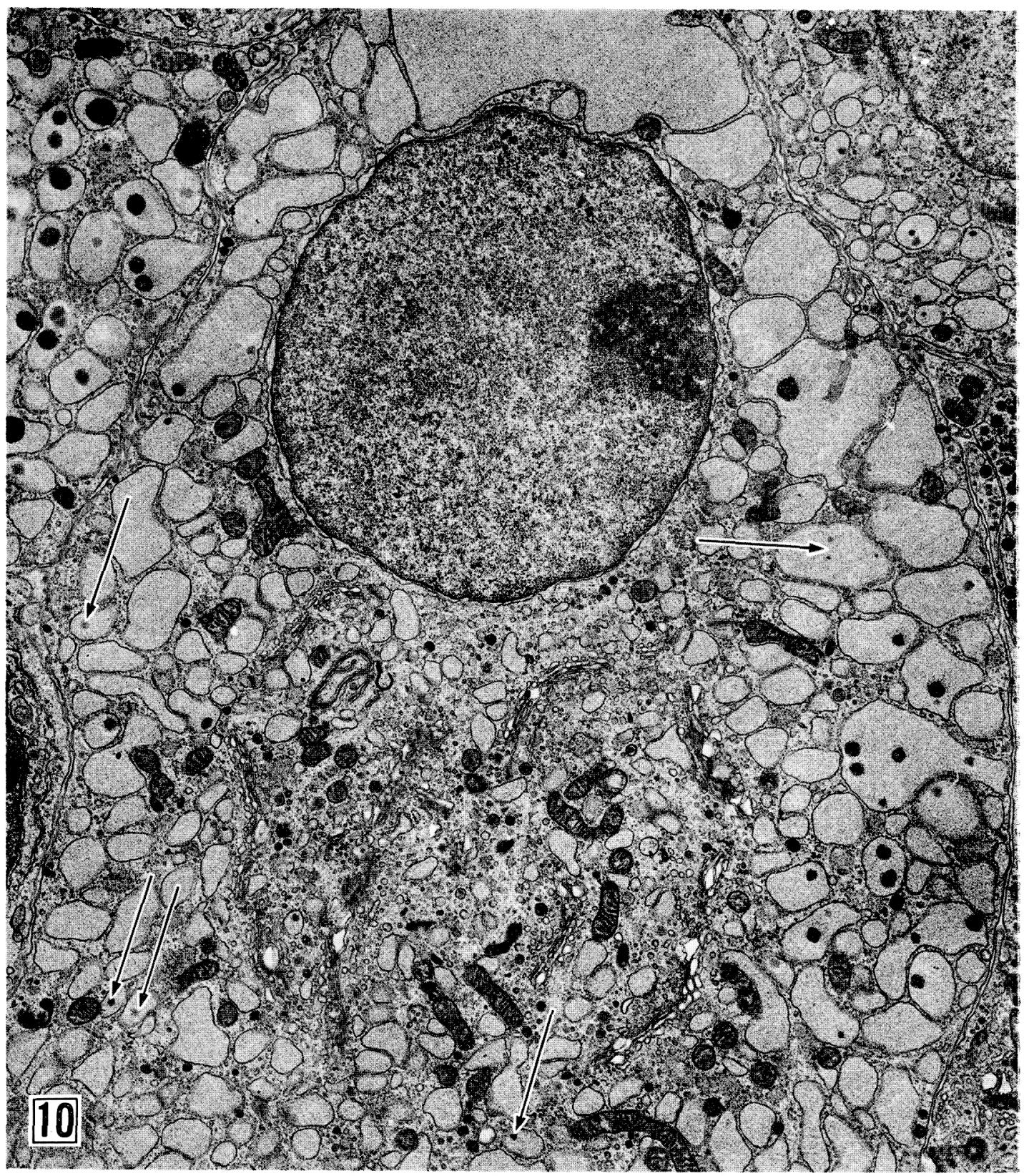

Fig. 10. A mature large TX-cell. This is characterized by numerous cisternae of various sizes and appearances. Intracisternal granules are frequently detected. The Golgi area shows some dilated lamellae, 14 days after TX. $\times 12000$. 
the definite closure. Scanty minute secretory granules below $50 \mathrm{~nm}$ in diameter remain at the cell margin probably after most of the secretory granules have been released (Fig. 9). Within 14 days, many large, mature TX-cells develop containing scanty secretory granules in the ground matrix. The circular arrangement of Golgi lamellae is prominent. The numerous small or large cisternae of RER, into which granules of low or high density are deposited (arrows in Fig. 10), occupy the cell-body except for the Golgi area. Lysosomal bodies sometimes appear in the Golgi area. The cisternae of Golgi lamellae recover from their definite closure to somewhat diliated form. Such mature TXcells increase in dimensions to a maximum diameter of more than $30 \mu \mathrm{m}$. As seen in Fig. 10, they are always oval in shape, not stellate. At 14 days after TX, the various steps of TX-cell development, viz., immature, young and mature types, were observed intermingled with a large number of III- and IV-type cells as well as a small number of typical II-type cells. However, mature TX-cells were not yet developed in large numbers before 14 days.

\section{Discussion}

If the II-type cells and TX-cells are included in a series of basophils, it is likely to be assumed that the III- and IV-type cells represent intervening cell types between the II-type cell and TX-cell. In our opinion, when primary deprivation of secretory granules from the II-type cells has proceeded to a profound degree after TX, the cells may be converted into round or oval basophils provided with the same cytological properties as the III- or IV-type cells. The present study demonstrated that within 12 $\mathrm{hr}$ to 1 day after TX, an abundance of III- and IV-type cells were electron-microscopically detected in the gland, in striking contrast to the infrequent detection of the II-type cells. According to the histometrical data by Arishima et al. (1978), in our laboratory, the number of the II-type cells is inversely related to that of the III- and IV-type cells within $12 \mathrm{hr}$ to 1 day after TX. Thus, the present electron-microscopic observation is in agreement with the histometrical study on the numerical variation of basophils by Arishima et al. The numerous III- and IV-type cells, most of which may have converted from II-type cells, were thereafter not only degranulated but also vesiculated again within 3 or 5 days after TX. On the other hand, some pre-existed IV-type cells before TX were going to retrograde. Both remarkable vesiculation and closure of Golgi lamellae in the IV-type cells may be concomitant changes necessary for the development into TX-cells. We cannot persistently deny a possibility that the degranulated thyrotrophs may directly transform into the immature TX-cells with vesiculation, although the reliable evidence of direct transformation was not provided in this study. The basophils demonstrated in Figs. 8 and 9 may have been regarded as the hyperfunctioning thyrotrophs corresponding to the immature TX-cells by Stratmann et al. (1973), Rosa and D'Angelo (1974), and Shiino and Rennels (1975), but they seem to us to rather belong to the IV-type basophils by their cytological property.

It was confirmed in this study that the transient degranulation from the II-type cells took place as early as $12 \mathrm{hr}$ after the operation. From radioimmunoassays of the serum TSH, LH and FSH concentrations carried out $3,6,12 \mathrm{hr} 1,3,5$ and 7 days after TX, Arishima et al. (1978) have demonstrated a biphasic response of serum TSH concentration after TX. A peak appeared at $12 \mathrm{hr}$ and the other one at 5 days after TX. Serum LH concentration, however, decreased conspicuously to less than one third of the normal value at 12 
$\mathrm{hr}$ and 1 day. This biphasic response of serum TSH may reflect the morphological changes of the primary deprivation of the secretory granules from the II-type cells and the secondary deprivation from the IV-type cells. Although there remain a small number of the granulated II-type cells at $12 \mathrm{hr}, 1$ and 3 days, they decrease in number or disappear at 5 days, in accordance with the peak of serum TSH concentration.

Yoshimura et al. (1977) proposed a working hypothesis of the secretory cycle of the basophil: Three glycoprotein hormones, i.e., $\mathrm{TSH}, \mathrm{LH}$ and $\mathrm{FSH}$, are not independently secreted by the so-called thyrotrophs, LH- and FSH-gonadotrophs respectively, but these three basophils are merely different functional phases of the same basophil. The IV-type cell was interpreted by them to be in the most active phase of secretion. If the IV-type cells are genuine FSH-secreting cells, a high incidence of the IV-type cells during the interval from 12 to 5 days after $\mathrm{TX}$ is contradictory to the inhibitory secretion of LH or FSH (Arishima et al., 1978). On the other hand, assuming that the IV-type cells can also secrete TSH, the evident deprivation of the secretory granules from the IV-type cells at 5 days is compatible with the subsequent rise of the serum TSH concentration at that time.

In general, TX and thiouracil treatment act chronically upon almost all pituitary cells. Their common changes are both degranulation and vesiculation of cells. A deficiency of basal metabolism-regulating hormone i.e., thyroxine, causes remarkable vesiculation in many pituitary cells in a manner different from the developmental process of castration cells. Specifically degranulated acidophils are also facilitated to vesiculate under thyroxine deficiency, while various stages of vesiculated basophils easily occur concomitantly with the appearance of TX-cells. The pre-existed basophils, however, quickly degenerate after TX. During the chronic phase after TX, all the pituitary cells finally have homologous structures, represented by severe vesiculation, so that it is difficult to identify the original nature of the cell (Yoshimura et al., 1973a and b). The closure of Golgi lamellae is evident in the immature TXcells, but the moderate recovery from the closure led to the mature TX-cells.

Concerning the function of TX-cells, Shiino et al. (1973) concluded that TRH caused TX-cells to release their secretory granules by the usual process of exocytosis or granule extrusion. Almost all of the TX-cells, however, failed to stain immunochemically with antibody to TSH at the light microscopic level (Baker and $\mathrm{Yu}$, 1971). Baker (1975) described in his review that, in the absence of thyroxine, intracellular maturation of TSH was impaired in the vacuolated thyrotrophs with the result that newly formed polypeptides backed up in the cisternae of endoplasmic reticulum. According to the view of Farquhar (1971), there is a defect in the mechanism of transport between RER and the Golgi complex in TX-cells, and as the time after TX is prolonged, the amount of secretory material increases in the cisternae of RER, taking the form of intracisternal granules. Roche and Zambrano (1974) demonstrated that puromycin and actinomycin-D inhibited the transport of secretory materials from the RER to the Golgi apparatus in TRH stimulated thyrotrophs. As to the discharge of intracisternal granules, Farquhar (1971) indicated that in thyroidectomized rats the replacement of thyroxine removed the block in the transport between RER and the Golgi complex so that synthesized proteins reached the Golgi area where the secretory granules are to be formed. Thus, thyroxine facilitates the intracellular transport of intracisternal granules in TX-cells, but inhibits both TSH synthesis (Tonoue and Yamamoto, 1967a and b) and discharge 
(D'Angelo, 1969). There is little or no evidence of autophagy of the intracisternal granules or of direct fusion with lysosomes in the thyroidectomized-thyroxine treated rats. The method by which the intracisternal granules gain access to lysosomes has not been established with certainty (Farquhar, 1971). Our present finding that the Golgi lamellae are constantly narrow in the immature TX-cells, is compatible with the views of Farquhar (1971) and Roche and Zambrano (1974).

Recently, Moriarity and Tobin (1976) demonstrated that the TX-cells were stained immunohistochemically with anti-rat TSH at the electron-microscopic level in rats 45 days after TX. Immunoreactive fine particles were deposited on the intracisternal granules contained in the big cisternae (type I TX-cell) as well as in the small ones scattered in the ground matrix (type II TX-cell). Further, in the animals treated with $\mathrm{T}_{4}$ in a dose of $0.1 \mu \mathrm{g}$ for 4 days, the immunoreactive particles were aggregated to form large homogenous intracisternal granules, but sometimes positive reactions on the extracisternal granules were seen. The present findings, together with studies cited above, suggest that the TX cells may be dysfunctioning basophils which have completed their secretory activity, rather than hyperfuntioning thyrotrophs. As long as the circulating thyroxine remains at a low level, the TX cells have not returned to their normal thyrotroph state. Hyperfunctioning thyrotrophs may be tentatively speculated from our present electronmicroscopy to belong to the IV-type basophils.

\section{References}

Arishima, K., M. Suzuki, M. Yokoyama and F. Yoshimura (1978). Endocrinol. Japon. 25, 87.

Baker, B. L. and Y. Y. Yu (1971). Endocrinology 89, 996.

Baker, B. L. Handbook of Physiology. Sect. 7. Endocrinology, Vol. IV, Part 1. Am. Physiol. Soc. Washington, p. 45 (1975).

D'Angelo, S. A. (1969). Endocrinology 84, 632.

Davis, S. L. and M. L. Borger (1973). ibid. 92, 1735.

Elftman, H. (1958). Anat. Rec. 131, 119.

Farquhar, M. G. (1971). Memoirs of Soc. Endocrinol. 19, 79.

Goluboff, L. G., M. E. MacRae, C. Ezrin and E. A. Sellers (1970). Endocrinology 87, 1113.

Mess, B. (1958). Endokrinologie 35, 296.

Moriarty, G. C. and R. B. Tobin (1976). J. Histochem. and Cytochem. 24, 1149.

Roche, C. and D. Zambrano (1974). J. Ultrastr. Res. 48, 1.

Rosa, C. C. and S. A. D'Angelo (1974). Amer. J. Anat. 135, 33.

Salaman, D. F. (1964). J. Endocr. 29, 283.

Shiino, M., M. G. Williams and E. G. Rennels (1973). Z. Zellforsch. 138, 327.

Shiino, M. and E. G. Rennels. Electron Microscopic Concept of Secretion (edited by M. Hess), John Wiley Sons, Inc. p. 271 (1975).

Stratmann, I. E., C. Ezrin, S. A. Seller and G. T. Simon (1972). Endocrinology 90, 728.

Stratmann, I. E., C. Ezrin, K. Kovacs and E. A. Sellers (1973). Z. Zellforsch. 145, 23.

Tonoue, T. and K. Yamamoto (1967a). Endocrino$\log y 81,101$.

Tonoue, T. and K. Yamamoto (1967b). ibid. 81, 1029.

Yoshimura, F., K. Harumiya, H. Yachi, T. Soji and M. Yokoyama (1973a). Endocrinol. Japon. 20, 181.

Yoshimura, F., K. Harumiya, T. Soji, M. Yokoyama and T. Kumagai (1973b). ibid. 20, 249.

Yoshimura, F., T. Soji, T. Kumagai and M. Yokoyama (1977). ibid. 24, 185. 